\title{
CORRESPONDENCE
}

\section{PRESENT-DAY VOLCANICITY AND CLIMATIC CHANGE}

SIR,-It is claimed by some writers (e.g. Humphries, 1913, and Fuchs, 1947) that volcanic eruptions can affect the amount of the sun's radiation received by the earth's surface. According to Humphries, single explosions of modern volcanoes can affect the sun's radiation throughout the world for periods of two to three years; Fuchs bases a theoretical explanation of Pleistocene climatic oscillations on the assumption that large-scale volcanic activity spread over $a^{\prime}$ long period may be sufficient to cause a marked lowering of the world's temperatures.

Because of the great importance of the implications that may be drawn from these statements, it seems advisable to study the immediate effect of modern volcanic eruptions over world temperatures in the light of the more complete climatic records now available. Thanks to Clayton (1944) there is now a comprehensive body of world weather records made easily accessible, and an enormous mass of detailed material of a more localized nature has become available.

The three outstanding volcanic eruptions of recent years were selected for special study : they were the eruption of the Krakatoa in 1883, that of Katmai in 1912, and that of the Southern Andes in 1921.

It takes a very short time for the erupted dust to reach fairly high regions of the atmosphere. It is assumed that it takes a longer time for this dust to spread over large areas, where alone its blanketing power would be of world-wide importance. For this reason the immediate approach to the problem was made by considering world temperatures in the year following the eruption. The analysis was simplified by grouping together all the records which showed temperatures below the average for the year, and all the records which showed temperatures above the average.

Text-fig. 1 shows the state of our knowledge of world temperatures for the year 1884, following the great explosion of Krakatoa. Most of Western and Central Europe actually experienced temperatures above the average, and so did North-Eastern Asia, the better known part of Alaska, and a section of the Eastern United States. In the Southern Hemisphere, Eastern Australia and most of Argentina were also warmer than usual during that year. Russia, Siberia, India, China, Canada, and most of the United States were cooler than average. So were Chile, parts of Australia, and Cape Province. Perth, W.A., recorded exactly the average temperature for the year.

Judging by area alone it may be said that the area having temperatures below average in 1884 was greater than the area having temperatures above average. But is this fact significant ? 


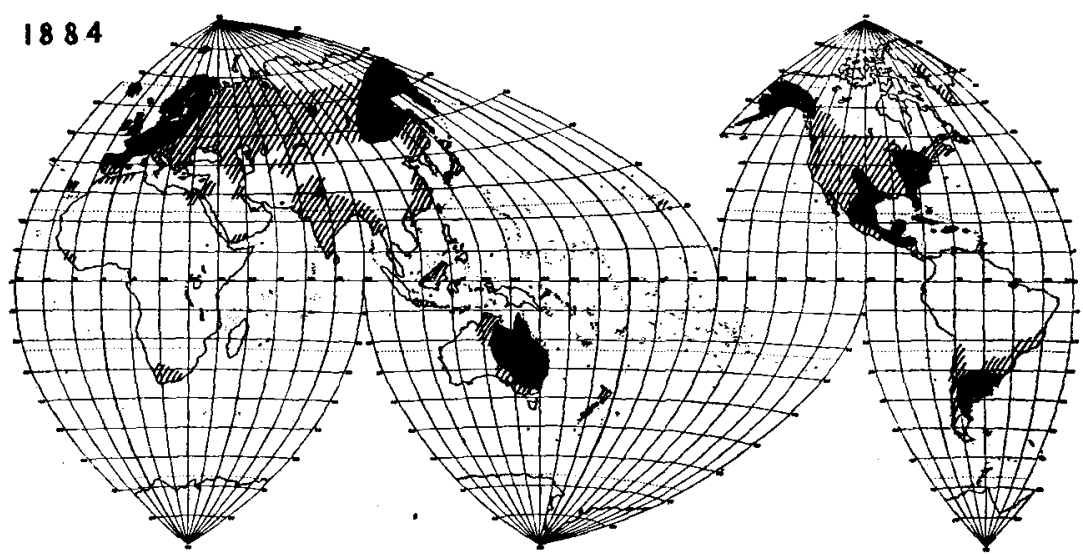

TexT-FIG, 1.-Regions with temperatures above average (black) and below average (shaded) in the year following that of the Krakatoa explosion.

One may study the records of the chief stations showing temperatures below average in 1884 . The following table gives the deviations from the mean temperature in the few years preceding and following the great explosion. The temperatures are expressed in ${ }^{\circ} \mathrm{C}$.

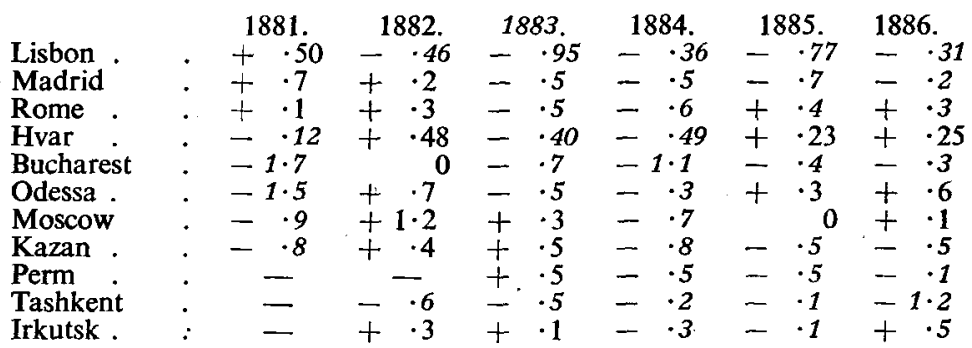

Farther east one reaches the zone where 1884 brought temperatures above normal. It is clear that the wave of temperatures below normal had already begun in 1883 in Southern Europe, and could not possibly be due to an eruption taking place in the same year thousands of miles farther east.

North American temperature records are given below in ${ }^{\circ} \mathbf{F}$. as deviations from the normal.

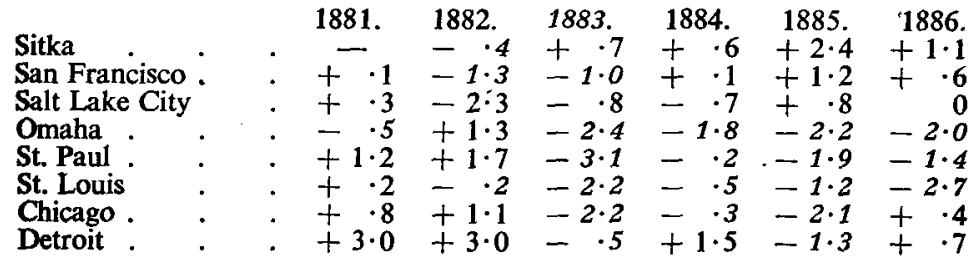


The series could be continued with records for localities farther east and south which had 1884 temperatures near or above the normal. The cool period began in 1882 in the north-west, and in 1883 on the Great Plains and farther east. But it must be stressed that any series of meteorological records shows variations above or below the average. Cool years were experienced from 1873 to 1876 , from 1883 to 1888 , from 1891 to 1893 in Omaha, the locality which would best bear out the "cooling from volcanic dust " theory according to the table given

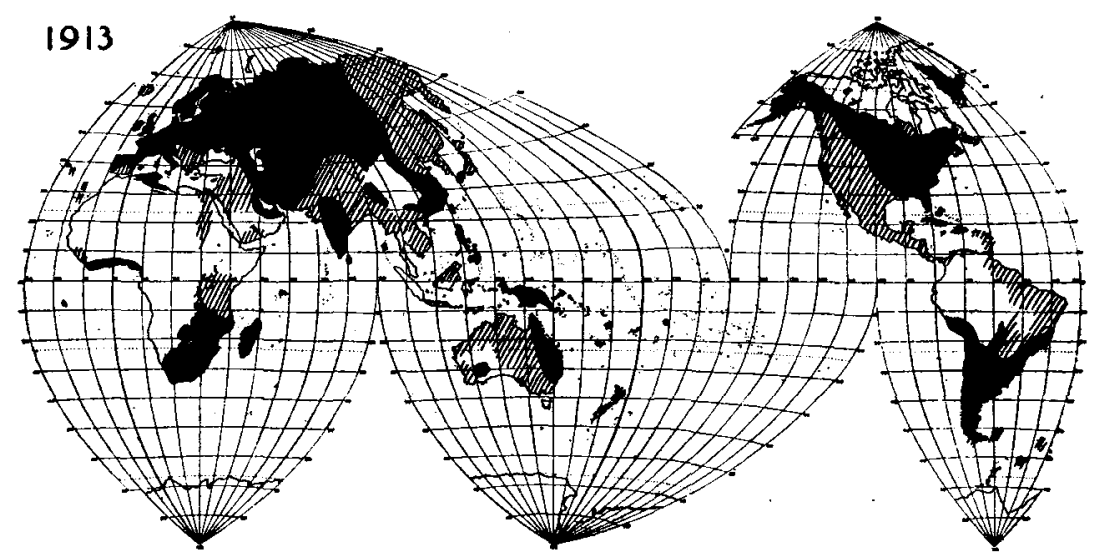

TeXT-Fig. 2.- Regions with temperatures above average (black) and below average (shaded) in the year following that of the Katmai eruption.

above. New York, for instance, had cool periods in the same years as Omaha, and in addition from 1895 to 1900 . But localities in other countries had warm periods during the same years, or alternate warm and cool periods: Scandinavian records could be quoted as an example.

It may be said that records for the years immediately following 1883 are not very numerous, and not always complete. It is desirable to study world temperatures after the Katmai eruption of 1912, and Text-fig. 2 has been constructed for this purpose. It shows that during that year a larger area had temperatures above normal (black) than below (shaded).

It is unnecessary to give a table for the years preceding and following the 1912 eruption, as was done for those preceding and following the 1883 one : the mass of data used in compiling the map hardly requires any further elaboration. But a more convincing proof could come from an analysis of temperature records for Alaskan stations, which should have immediately felt the effect of the volcanic dust if such effect had been noticeable. 


\begin{tabular}{|c|c|c|c|c|c|c|}
\hline \multirow{2}{*}{\multicolumn{2}{|c|}{ Dutch Harbour. }} & 1912. & 1913. & 1914. & 1915. & 1916. \\
\hline & & -4 & & $+2 \cdot 0$ & $\overrightarrow{2}$ & - \\
\hline & & $+3 \cdot 9$ & & $+2 \cdot 6$ & $+3 \cdot 4$ & + \\
\hline Juneau & & $+2 \cdot 3$ & +.7 & -.5 & +2.5 & - \\
\hline Nome & • & $+4 \cdot 4$ & +2.9 & $+3 \cdot 6$ & - & $\sim$ \\
\hline Sitka & . & +1.9 & $+1 \cdot 0$ & $+1 \cdot 6$ & +3.5 & -.9 \\
\hline Tanana & . & $+4 \cdot 5$ & $+\cdot 2$ & +3 & $+2 \cdot 5$ & $\cdot 3$ \\
\hline & & +2 & .8 & & $+1 \cdot 0$ & $-1 \cdot 2$ \\
\hline
\end{tabular}

It must in fairness be pointed out that 1913 was a cooler year than 1912 and 1914, but even so temperatures did not fall below normal except at Eagle and Valdez.

Text-fig. 3, constructed for the year following the Andean eruption of 1921, also fails to show any substantial cooling of the earth's surface for that year.

Summing up, it may be said that there appears to be no climatological evidence to support the theory that volcanic eruptions may cause

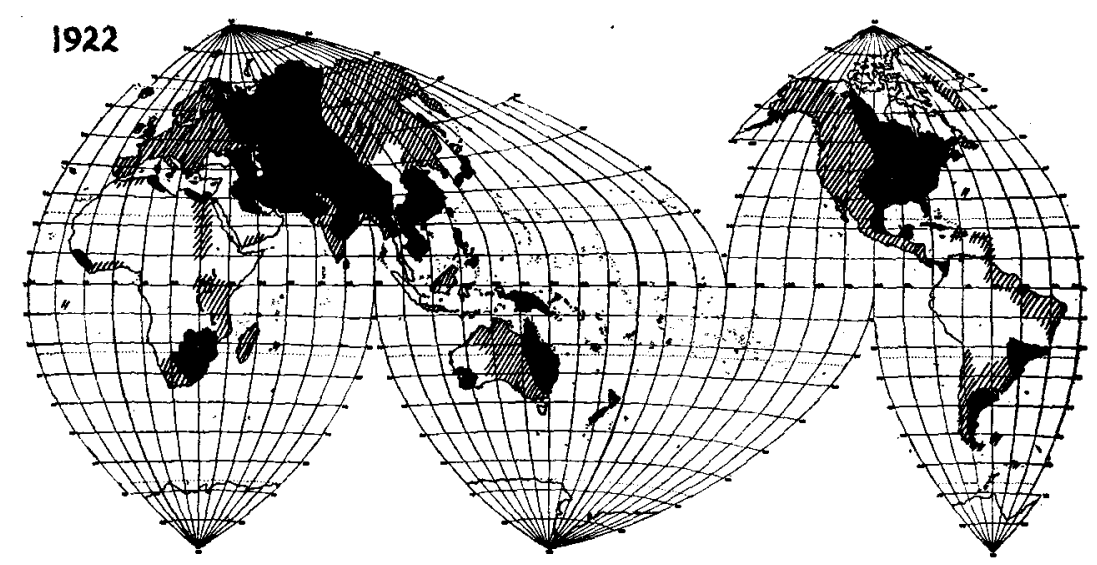

TEXT-FIG. 3. - Regions with temperatures above average (black) and below average (shaded) in the year following that of the Andean eruption.

a lowering of temperatures even in the year immediately following the eruptions and even in regions very near to the erupting volcano. Until more convincing evidence is assembled and produced any attempt to extrapolate to Pleistocene or other periods seems very risky.

UNIVERSITY OF WeSTERn AUSTRALIA.

J. Gentilli. 23rd February, 1948.

\section{BIBLIOGRAPHY}

Clayton, H. H., 1944. World Weather Records, Washington.

FuCHs, V. E., 1947. Geol. Mag., lxxxiv, pp. 321-7.

HUMPHRIES, W. J., 1913. Journ. Frankl. Inst., 176, p. 131. 